\title{
Incontinence: Physical Activity as a Supporting Preventive Approach
}

\author{
Aletha Caetano \\ Faculdade de EducaçãoFísica- Universidade Estadual de Campinas - UNICAMP \\ Brazil
}

\section{Introduction}

Aerobic exercises, as well as those for muscle strength and flexibility, might play a positive role in preventing and treating heart diseases, hypertension, osteoporosis, obesity and diabetes, to name a few, especially when practiced on a regular basis, under supervision and properly adapted to each individual (Carrol \& Dudfield, 2004). Furthermore, the benefits brought by physical activity reach as far as the emotional aspects of the individual and help prevent the negative effects of stress, reduce tensions, enhance mood, lower the symptoms of stress and anxiety (Gorayeb \& Turibio, 1999), and, eventually, improve health and boost the quality of life. According to the American Heart Association, the lack of physical activity can lead to a higher mortality and morbidity rate (America Heart Association, [AHA], 2007) Disengagement in physical activities is quite often associated to sedentary habits which might lead up to degenerative-chronic diseases, offering great risk to the population as a whole (Who, 1995). There are evidences that the incidence of these pathologies, plus other health conditions, including diabetes mellitus, osteoporosis, some cancers, obesity, the maintenance of body mass index (BMI) and hypertension, can be reduced by encouraging a more active life style, based on a constant and regular physical practice.

Urinary incontinence is a disease which interferes with the practice of physical activities, mostly among women; since physical workouts may trigger involuntary episodes and urinary leaking, incontinent women are likely to be caught on an embarrassing and uncomfortable spot while exercising (Brown \& Miller, 2001; Caetano et al., 2009a). This is a huge limitation for the practice of physical exercises by women (especially those with moderate to severe incontinence), and dangerous for female health (Nygaard et al., 2005; Stach-Lempinem et al., 2004). Significant morbidity and mortality prevalence has been reported among women with urinary incontinence (Mullins \& Subak, 2005). Putting it this way, quitting physical activities and sports practice might lead up to a sedentary life style, a major risk for and cause of several diseases.

Given that, this chapter aims to: (1) review publications on important available data about urinary incontinence as related to sports and physical activities.; (2) based on a systematic program of physical activities, introduce strategies which enable the Physical Education instructor and other professionals to take supplementary action in order to help prevent urinary incontinence in women and lower its prevalence rate. 


\section{Urinary incontinence}

Urinary Incontinence was first seen as a disease by the International Classification of Diseases (ICD/WHO) in 1998; up until then, it was treated as a symptom. The International Continence Society currently defines urinary incontinence as "a complaint of any unintended urinary leaking" (Abrams et al., 2003). It is estimated that 200 million people across the world show some sort of urinary incontinence. Its incidence is twice as higher in women, due to anatomic reasons, hormonal changes and as an after-effect of pregnancies and baby deliveries which can relocate and weaken the pelvic muscles. (Simeonova et al., 1999). According to Ortiz (2004), one out of 4 women has already had an episode of urinary leaking. When considering the kind of population under study (features such as age, professional activity, incidence of chronic diseases, menopause), the kind of diagnosis applied, and the definition used during the investigations, urinary incontinence prevalence may range from $10 \%$ to $55 \%$ in 15 to 64 year-old females (Hunskaar et al., 2004). About 38\% of elderly females urinary leaking intense enough to be classified as a "urinary incontinence problem" within this group (Nygaard et al., 2007a). Just the same, the greatest incidence of urinary incontinence typically occurs in the years prior to or after the menopause, reaching its highest peak in 45 to 49 year-old women. Despite this high prevalence, less than $50 \%$ of these female patients look for medical treatment. Reasons for this might be as complex as shame and/or embarrassment and the belief that urinary incontinence, simply comes along with the ageing process (Mullins \& Subak, 2005).

Not only does urinary incontinence imply medical consequences, but high expenses and negative emotional effects as well. It has been shown that this condition demands a cost which might range from 16 to 26 billion dollars a year, including days off at work and the use of sanitary napkins and diapers (Hu et al., 2004). Emotional damages can be even more devastating, as most incontinent women hardly ever share this problem and usually prefer to deal with it on their own, "silently". About $80 \%$ of women with severe urinary incontinence show symptoms of depression, high anxiety and low self-esteem, including loneliness and sadness. Moreover, the embarrassment and shame that come along are responsible for their quitting social activities and sports as well as for their lack of sexual interest (Fultz et al.; 2003; Norton et al.; 1988), which might exacerbate negative emotions and feelings.

Among the different types of urinary incontinence, the most commonly identified are stress urinary incontinence, urge-incontinence and mixed incontinence. The first is most frequently seen in 25 to 49 year-old females. Mixed urinary incontinence is more common in middle-aged women (40 to 60 years old) while urge-incontinence is mostly identified in elderly women (Minassian et al., 2003). Stress urinary incontinence appears to be more frequent in physically active female, those who practice sports and/or exercise regularly.

\subsection{Stress urinary incontinence}

Guyton \& Hall (1997), characterize two main phases in urination: bladder filling or storage is the first, when there is an increase in the bladder wall pressure above limits; the voiding (urine flow) reflex occurs in the second phase, when the bladder is emptied and there should be a conscious signal of urinary urge. It is an autonomous reflex, integrated in the spinal cord which can be inhibited or facilitated by cortex centers or by the brainstem. In 
order to maintain urinary continence, the bladder must be complacent capable of storing hundreds of milliliters in volume, the urethra must be preserved and in a normal position, innervations must be intact, which is crucial for the sphincters integrity. A properly long urethra is also important, as it allows urethral mucosal coaptation which mechanically prevents the flowing of urine or the voiding. (Wei et al., 1999).

However, the female urinary continence mechanism is also supported by a healthy perineum structure, such as muscle and fascias (tissues) which provide structural framework for the internal organs as well as the closure of the pelvic opening. (AshtonMiller \& DeLancey, 2001). The perineum comprises all soft tissues that circle the pelvis and keep viscera in the upright position. In a simplistic analogy, the pelvic floor is compared to *the foundations of a house, the diaphragm would be the ceiling and the abdominal muscles would make the front and side walls, while the spinal muscles and cord would make the back walls" (Grosse \& Sengler, 2002). The pelvic floor muscles encompass three different layers (or plans), known as deep, middle and superficial. All layers, but the superficial, have voluntarily active muscle parts which can help keep continence when proper and supervised training takes place.

The deep layer consists of the main pelvic diaphragm, comprised by two muscles: the levator ani and the ischiococcygeus. The outward section of the levator ani is called elevator, its sphincter-like (consists of two hammock-like muscles - the pubococcygeus and the iliococcygeus) and has the support of the ischiococcygeus muscles; the inward section is formed by the pubovaginal and puborectal muscles. For the physical trainer, the levator ani is crucially important, as the pelvic floor muscle strength and quality can be improved by exercising this muscle.

The layer in the middle has three muscles: two deep transverse and the external urethral sphincter. The latter has the shape of a ring, circles the mid-third of the urethra and plays a fundamental role in the maintenance of continence. It's made of non-fatigable slow fibers which form the intra-urethral section plus a group of stretched muscles formed by slow fibers, fast and strong but highly fatigable fibers, called peri-urethral section. Despite being formed by striated fibers, the external sphincter is always in a state of contraction, helping to keep the pressure in a balanced level; in addition, it helps eliminate involuntary urinary flow as urinary needs can be controlled by strong and quick contractions.

Stress urinary incontinence is classified as the involuntary urine leaking as a result of physical exercises, physical efforts, sneezing and/or coughing (Abrams et al., 2002). It occurs when the urethral sphincter cannot withstand the urinary flow resulting from physical activities that increase intra-abdominal pressure; whenever a weakness or flaw occurs in the pelvic floor, there is an incorrect pressure transmission for the physical efforts, thus damaging the urinary continence mechanism and leading up to an unintended urinary leaking. This kind of incontinence is probably due to anatomic reasons; hypoestrogenism; after-effects of baby deliveries and pregnancies which might relocate and weaken the pelvic floor muscles. Other causes of stress urinary incontinence in women are: obesity; chronic diseases; gynecological surgeries; bowel obstruction; caffeine ingestion; smoking; hereditary reasons; medicinal drug ingestion (for example, alpha-adrenergic) and physical exercises. 


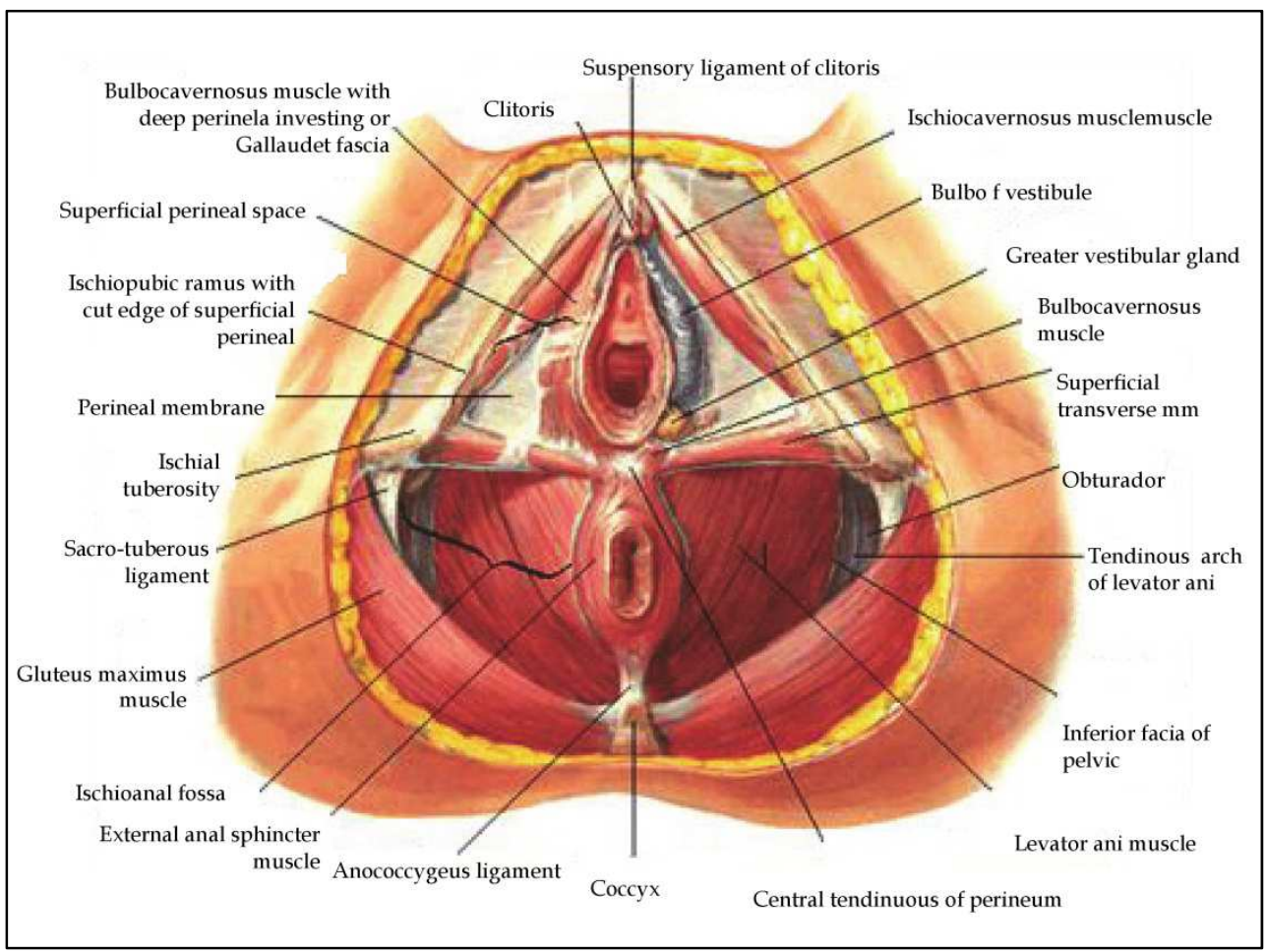

Fig. 1. Pelvic Floor Muscle -Source- Atlas of Human Anatomy(Frank H.Netter, 2010).

As mentioned earlier, stress urinary incontinence has lately been more frequently identified in physically active women. Though not conclusive, studies on this issue have reported that great effort and high impact exercises can enhance the chances for the development and worsening of stress urinary incontinence.

\section{Relationship between urinary incontinence and sports and physical exercise}

\subsection{Physical exercises as a risk factor for stress urinary incontinence}

Authors do believe that high impact exercise can represent a risk factor to the development of stress urinary incontinence (Bump \& Norton, 1998; Nygaard et al., 1994; Bo, 1992), however, studies and researches on the relationship between stress urinary incontinence and physical activities and sports are still quite rare and little is known about the impact of several exercises and sports on the pelvic floor. Previous studies showed two different hypothesis for the way high impact exercises affect the pelvic floor. One of them states that physical exercise may strengthen the pelvic floor muscles and, thus, help prevent stress urinary incontinence as it bolsters the muscles in charge of the continence. The second one, on the other hand, argues that physical exercises may overburden, strain and weaken the pelvic floor muscles and consider strenuous and high impact exercises (Bo, 2004b) as a risk 
factor for urinary incontinence. It is worth reminding that both hypothesis are related to young nulliparous elite athletes. Just the same, amenorrhea resulting from intense workout, eating disorders and/or both can foster urinary incontinence in athletes.

Some studies have associated urinary incontinence in nulliparous athletes with impact strength assimilation resulting from some activities. Long jumps allow the feet to touch the ground and may generate a maximum reaction force 16 times higher than body weight (Hay, 1993). This impact, a consequence of high impact exercises, may affect the continence mechanism by modifying the amount of strength transmitted to the pelvic floor. The shock transmission force, which occurs between the feet and the ground and is transferred to the pelvic floor, may foster incontinence in young nulliparous females, who do high impact exercises (Nygaard et al., 1996; Nygaard, 1997). Recently, O'Dell et al. (2007), analyzed the abdominal pressure during the use of hydraulic exercise machine; weight-lifting; floor exercises and jogging and comparing those exercise with abdominal pressure resulting from coughing in several individuals, the authors found out that, though different among subjects, the pressure on the pelvic floor during physical activities was lower than during coughing. Ree et al., (2007), verified that young nulliparous females with urinary incontinence symptoms showed fatigue in the PFM after performing strenuous physical activities for 90 minutes. According to the authors, studies about the impact of long term strenuous physical exercises on the pelvic floor among elite athletes should be carried out, once there has been a significant prevalence of stress urinary incontinence in this group (Bo, 2004a).

\subsection{Urinary incontinence prevalence in women}

\subsubsection{Athletes}

Studies on the relationship between urinary incontinence, sports and physical activities and the prevalence of this condition in elite athletes date back from the 90s. Since then, they have gradually called the attention of professionals from different areas of expertise. As aforementioned, longitudinal systematic studies are still necessary, in order to identify the pelvic floor reactions while long term sports and physical activities are being performed, considering different intensities and frequencies. All the same, up until now, researches have indicated that urinary incontinence complaints are quite common among elite athletes. The examined studies showed $6 \%$ to $80 \%$ urinary incontinence prevalence among 12 to 22 year-old athletes, depending on which sport was practiced. Gymnastics, running and trampoline were the ones with the most urinary leaking complaints. (Bo, 2004b; Bump \& Norton 1998; Eliasson et al., 2002; Jiang et al., 2004; Nygaard, et al., 1994; Nygaard et al., 1996;).

Nygaard et al., (1994), studied 156 athletes with an average age of 19,9 years; 28\% said they had experienced urinary leaking while practicing a sport. The most frequently mentioned was gymnastics $(67 \%)$, followed by basketball $(66 \%)$, tennis $(50 \%)$, hockey $(42 \%)$, trekking $(29 \%)$, swimming $(10 \%)$, volleyball $(9 \%)$, softball $(6 \%)$ and, lastly, golf $(0 \%)$. Jumping, high impact landings (or hitting the ground with high impact) and running were the physical activities with the highest incidence of urinary leaking. The jumping exercises with legs open, were a major complaint for $30 \%$ of the athletes, followed by tight-leg jumps (28\%). In the same research, around $40 \%$ of the athletes reported urinary leaking while practicing 
sports in high school and 17\% in junior high school. Another study showed that the athletes also complained about urinary leaking not only during sports practice but also while performing every-day activities. The author identified that over half of 291 athletes, with an average age of 22.8 years, reported urinary leaking in both situations (Thyssen at al., 2002). It is interesting to mention that most of the athletes participating on this research, who complained about urinary leaking only while practicing sports, admitted it, happened only during practice and not during competitions. The authors believe this is probably due to "a ritual" of emptying the bladder and of drinking less liquid before competitions.

Urinary incontinence prevalence was also compared between a group of 660 athletes, belonging to a junior and senior national team (of 38 different sports) and a control group of 765 non-athlete females (Bo \& Borgen, 2001). Their age ranged from 15 to 39 years. The majority was nulliparous, only $4 \%$ had had children. As for the non-athletes, one third had already given birth. Hence, data about childbirth must be taken into consideration and were more significant in the control group. There was no meaningful difference in the urinary incontinence prevalence in athletes and non-athletes: $41 \%$ and $39 \%$, respectively. $27 \%$ of the athletes complained about urinary leaking while coughing, sneezing and laughing; $29 \%$ reported incontinence during physical activities and 15\% during sudden moves or standing up.

The highest prevalence of urinary incontinence complaints during exercises was detected among trampoline professionals; $80 \%$ out of 35 nulliparous athletes, average age 15 (12-22 years old), complained about incontinence while jumping on the trampoline (Elliason et al., 2002). Athletes who complained about incontinence reported that urinary leaking was first noticed after two and a half years of practice. In this study, urinary incontinence was associated to the years of practice, age and duration and frequency of training. Incontinent athletes were older and had more frequent and longer trainings than athletes who had no symptoms of incontinence. During tests, incontinent athletes had more difficulty with voluntary voiding control by contracting the pelvic floor muscles than the other group with no incontinence symptoms. These athletes are likely to have been exposed to constant effort and impact; on the long run, due to the lack of training, the muscles responsible for continence lost their strength, leading up to urinary incontinence. In a more recent study, the same author (Eliasson et al., 2008) identified a high urinary incontinence prevalence in trampoline athletes (18-44 years old) during a competition. The author divided the athletes in two groups, according to the exercise intensity; 85 women performed high impact jumps and 220 performed low impact jumps. Among those who complained about urinary incontinence while practicing the sport, $76 \%$ still complain about the same symptoms; of these, $57 \%$ belong to the high impact jump group and $48 \%$ to the low impact jump group. The author also detected prospective reasons for urinary incontinence development in this group; similarly to his prior study (Elliasson et al., 2002), the author reported that the frequency and intensity of the exercises, age of first menstrual period, bowel obstruction and inability of voiding control were important factors for urinary incontinence. Hence, the practice of this sport (trampoline) without simultaneous and proper training for the strengthening of pelvic floor muscles may represent a risk factor for urinary incontinence onset, during and after the aforesaid practice.

A retrospective study including 104 athletes who were in the Olympics, in the 60s up until 1976, detected that 35\% reported urinary leaking during high impact activities, such as 
gymnastics and trekking. Swimming was considered a low impact sport, responsible for only $4.5 \%$ of the complaints. (Nygaard, 1997). All the same, the author concluded that high impact activities do not lead up to a significant urinary incontinence in the adulthood of the women belonging to the studied group. Actually, in a more recent retrospective study, authors investigated urinary incontinence complaint in 331 retired athletes as compared to a 640 female control group. Currently, 36.5\% of the athletes complained about stress urinary incontinence and $36.9 \%$ of the control group had the same complaint. There was no meaningful difference between the two groups. Yet, after a more thorough and specific analysis on the athletes, the results indicated that urinary incontinence, when identified during the sports practice, can be a strong signal of future urinary problems in adulthood (Bo \& Borgen, 2001).

Another issue, not less important and that must be taken into consideration in the complex relation of urinary incontinence prevalence among professional athletes is the much less studied eating disorder. This condition was detected in $20 \%$ of the athletes and only in $9 \%$ of the control group. As for stress urinary incontinence, it was reported by $49 \%$ of the athletes and by $38.8 \%$ of the control group. Urinary incontinence in women with eating disorders is likely to be associated with self-induced vomiting (a particular feature of such a disorder), which applies significant and repetitive pressure over the pelvic floor and, eventually, damages it. High impact sports practice without proper supervision might promote urinary incontinence in athletes with eating disorders (Bo \& Borgen, 2001; Hextal et al.,1999). New researches should be carried out in order to identify the relationships between both urinary incontinent and eating disorder symptoms, considering different sports and physical activities

\subsubsection{Non-athletes}

Similarly to the aforesaid about professional athletes, not until 2008 were studies and researches on urinary incontinence and sports and physical activities among non-athletes conducted. These few researches studied 18 to 65 year-old women, non-professional athletes, who mostly complained about incontinence while running and doing high impact sports; still, urinary leaking was also observed during everyday activities. Bo et al. (1989) observed a major difference between participants who practiced physical activities and those who didn't. Two different groups were compared: students whose major was physical education and others majoring in nutrition. $(A=22.9 ; 19-59)$. Aspects such as age, childbirth and different physical exercises were considered. About $26 \%$ of the physical education students reported urinary leaking as compared to $19 \%$ of the nutrition students. According to the authors, this was not significant. However, when physical education students worked out more than three times a week, urinary incontinence prevalence increased up to $31 \%$, a major difference when compared to the $10 \%$ presented by sedentary nutrition students. Nygaard et al., (1990) studied 326 women, 20-65 years old, $(A=38,5)$ who exercised regularly; $47 \%$ had already noticed some kind of urinary leaking throughout life. In this study, no important connection was established between urinary incontinence and profession, educational background, weight, height or menopause. About $33 \%$ of the women reported incontinence while exercising. These women usually exercised three times a week during 30 to 60 minutes. Incontinence was most frequent while running; $38 \%$ of the women complained about urinary leaking while doing high impact aerobic exercises. 
Another study including 3,364 women, 18 to 60 years old, detected that 1 out of 7 were incontinent while performing any kind of physical activity. (36). High urinary incontinence prevalence is also identified in women who belong to the US Army and US Air Force (Davis, 1999; Fischer \& Berg, 1999). 31\% out of the 563 female soldiers under observation complained about urinary leaking during physical and field drilling. Around $40 \%$ of them also complained about it during recreational activities. Aerobic exercises ranked highest in complaints $(42 \%)$, followed by running (35\%), weight-lifting (18\%), jogging (21\%), biking $(8 \%)$, swimming (5\%) and lastly, golf $(3 \%)$.

Salvatore et al., (2009) recently studied 679 female soldiers aiming to check urinary incontinence prevalence during recreational activities. The authors reported that stress urinary incontinence was detected in $14.9 \%$ of the subjects; out of this total, $31.7 \%$ complained about incontinence during sports practice and $10.4 \%$ considered their incontinence severe enough to limit or discourage their activities. The sport with the most complaints, $(16.6 \%)$ was basketball, followed by running $(15 \%)$. Body Mass Index and childbirth were connected to urinary linking. Also, data about studies on physical exercises and sports instructors were found. The first study with Physical Education teachers was done by (Santos, et al., 2009). We studied nulliparous students, 19 to 26 years old. $20.7 \%$ of them had already had urinary leaking before while practicing their sport and ranked it as a 2.3 leaking (in a scale of 0 to 10), being no problem at all and 10 being a severe problem). In this study, we came to the conclusion that, though urinary incontinence was quite frequent, the group didn't consider it a problem. More recently, 685 Pilates and Yoga instructors, with an average age of 32.7 years (18 to 68 years old) were studied; the authors identified a $26,4 \%$ prevalence of incontinence complaints. Among incontinent women, 15.3\% reported urinary leaking during physical activities and $10.9 \%$ while sneezing or coughing. Hence, pelvic floor training is recommended not only for athletes and women who leisurely practice sports or physical activities, but also for instructors, coaches, trainers and teachers (Bo et al., 2011; Santos, et al., 2009.)

\subsection{Urinary incontinence impact on physical activity}

Unexpected and involuntary episodes of urinary leaking which may happen during physical activities may put incontinent women on an embarrassing and uncomfortable spot. According to studies, nearly $20 \%$ females give up (Nygaard et al., 1990) or limit their favorite sports and physical activities due to urinary incontinence. (Salvatore et al., 2009). A longitudinal study on female health (Australian Longitudinal Study on Women's Health(ALSWH) reported that $27 \%$ females who practiced physical exercises showed urinary incontinence symptoms(> 40\% were middle aged women and $16 \%$ were young or elderly); a percentage which supports previously discussed studies. Most incontinent women said they gave up sports practice due to their incontinence. According to the authors, the highest incidence of disengagement was among $\geq$ to 48 year-old women. Some authors consider that this might be even higher among women in the post menopause (Eliasson et al., 2002; Salvatore et al., 2009). Furthermore, the greater the concerns towards incontinence during exercise performances, the higher the frequency of urinary leaking episodes (Fultz et al., 2003) leading to an increase in giving up physical activities. More specifically, severe urinary incontinence symptoms strongly hamper the practice of physical activities, (Brown \& Miller, 
2001; Nygaard et al., 2005), increasing sedentary habits and exposing the population to health conditions associated with sedentary life styles.

On the other hand, encouraging physical activities can have a positive effect on incontinent women's attitude towards exercising. However successful urinary incontinence treatment was, women who had always exercised, continued doing so. Likewise, those who had never exercised before did not change their habits. According to information gathered from women who participated in the research, the more active ones looked for medical treatment because they wanted to lower and prevent urinary incontinence and, thus, keep up with their exercises (Stach-Lempinen et al., 2004).This attitude might be associated to a high motivation in doing physical activities. According to Bo et al., (1989), more motivated women tend to take urinary leaking for granted, while the less motivated ones make a big deal out of it. Professional athletes seem to be more motivated for sports and physical activities and perform more stressing exercises than those who practice sports leisurely. The first continue practicing, despite incontinence and other problems (Nygaard et al., 2005). Researches have found that women who did not quit physical activities because of urinary incontinence, worked out a way to prevent urinary leaking while exercising. Their usual strategies were: the use of sanitary napkins and diapers, emptying the bladder before practice and competitions, liquid ingestion restrictions, and choosing a different exercise to perform. This last strategy means that exercises which might facilitate urinary leaking (jumping, running) are avoided, and these women start to practice low impact sports, such as walking, biking and swimming (Nygaard et al., 1990; Thyssen et al., 2002). Besides these strategies, women studied by Salvatore et al., (2009) chose exercises to strengthen the pelvic floor muscles as a way to prevent incontinence during physical activities. These "adaptation" strategies, however, did not seem to be effective enough to prevent that they quit exercising. Several times, sanitary napkins cannot avoid urinary leaking and, after the first incontinence, women tend to give up physical practice (Tata, 1998).

In a prospective study of 314 women with pelvic organ prolapse and stress urinary incontinence, the authors investigated if women who had undergone sacrocolpopexy surgery a year before, changed physical activities. One year after the surgery, $36 \%$ of the women increased the intensity of the exercises, $18 \%$ lowered and $47 \%$ kept the same intensity. The authors reported that most women who considered that the pelvic floor organ prolapse could prevent or restrict exercising changed their view after the surgery.

However, it is worth saying that a few participants kept on limiting their physical activities, despite de surgery, due to fear of prolapse recurring and to their doctor's advice (Nygaard et al., 2007b; Nygaard et al., 2008).Bottom line, when women themselves limit the frequency and intensity of physical exercises, they drift apart from the benefits of a systematic practice for their overall health.

\section{Benefits of physical exercises for urinary incontinence}

\subsection{Pelvic floor muscle training}

The most widely known exercises which prevent and treat urinary incontinence were created by Dr. Arnold Kegel in the fifities. This American gynecologist was the first to scientifically use exercises to strengthen the pelvic floor muscles in order to improve urinary 
incontinence mechanisms. These exercises improve the perineum muscle contraction, giving it more power (strong and fast), increase urethral compression against the pubic symphysis, increase intra-urethral pressure when intra-abdominal pressure is increased, help pelvic muscle hypertrophy and increase the volume of such muscles. Hence, structural support of this body area becomes more effective and prevents the urethra from descending when intra-abdominal pressure increases and, consequently, decreasing urinary leaking. Kegel (1948), observed that, apart from decreasing urinary incontinence, his exercises had positive effects on female sexual desire. His exercises are, therefore, based on the strengthening of the pelvic floor muscles (Palma \& Ricetto, 1999). The pelvic floor muscles should support the viscera in the upright position and maintain urinary continence as well. So, they should be kept strong and in perfect condition. Still, in order to effectively perform these exercises, Levi-D'Ancona (2001) states that incontinent women should learn to contract and relax these muscles, once they are not usually used, and that many women have difficulties with their voluntary contraction (Moen et al., 2007).

Since Kegel first published the development of these exercises, they have been widely used and quoted in medical academic literature; however, as of then, it is also possible to find not only different techniques and systematization (that is, frequency, intensity, repetitions and associations) but also different instructions given to patients in scientific literature. According to theory on the development of exercises to treat stress urinary incontinence, the aim is to boost pelvic floor muscle (PFM) strength, coordination, speed and resistance in order to keep structures in an adequate position whenever there is an effort which causes intra-abdominal pressure increase and, thus, keeping a proper urethral closure strength. (Ashton-Miller et al., 2001).

In literature, it's possible to find different protocols to strengthen the pelvic floor through exercises. Most studies follow protocols with instructions based on quick and slow contractions, in 3 steps, ranging from 8 to 12 repetitions; isometric contractions with maximum contraction held for 6 to 8 seconds, 2 to 4 times a week. According to different authors, PFM strength increased after a period which varied from 4 weeks to 6 months. Another procedure used to strengthen the PFM is training only with isometric contractions with maximum contraction for a period of 6 weeks to 6 months. The study also advised women to perform the exercises at home; according to others, women had better attend weekly or monthly group training; some advise a doctor's appointment once in 6 months and others see no need for group training or appointment with a doctor. Most protocols or training methods were reported as positive for the improvement or cure of incontinence symptoms presented by some of the subjects of their studies. "Skill training" is also a procedure which may help strengthen and train the PFM; it implies the learning of motor skills which favor a more effective contraction time of the PFM before an activity that increases abdominal pressure followed by a possible urinary leaking (whenever there are injured and/or weakened muscles). Bo et al., have named this a motor learning approach. Though "skill training" has been quoted as useful for PFM training, few information on the specificity of these exercises have been made available. Other studies (Arvonen et al., 2000; Balmforth et al., 2004; Dumoulin et al., 2004; Hay-Smith et al., 2002; Parkkinen et al., 2004;) Turkan, 2005), even match up PFM strengthening exercises with "skill training", getting positive results, but as the reports don't follow a standard protocol, comparisons become invalid. The role of the abdominal muscles has also been discussed, as far as PFM training 
and strengthening are concerned (Cammu \& Nylen, 1998; Johnson, 2001; Pieber et al., 1995). However, studies available in literature do not reach an agreement, and as evidence is not strong enough, abdominal muscle training is not included in the treatment of urinary incontinence (Bo et al., 2009).

The benefits of PFM training and strengthening could be seen when they were performed with no other technique (reference); or when combined with techniques such as biofeedback; electrical stimulation; with vaginal weight or cones; with the combination of two techniques, such as biofeedback + electrical stimulation; and also with the combination of three techniques: biofeedback + electrical stimulation + with vaginal weights and cones. More detailed data on the researches aforementioned can be found in publications by Neumann et al. (2006). Notwithstanding, no study linking PFM training and strengthening to a systematic exercise program outside the therapeutic context was identified during this review.

\subsection{Pelvic floor exercises during sports practice}

Only a few researches in which training for the pelvic floor muscle strengthening has simultaneously occurred during sports practice were pointed out. As aforesaid, there is little knowledge about how pelvic muscles work during sports and physical activity practice. According to some authors, most physical activities do not involve pelvic muscle voluntary contraction during the performance of exercises which increase intra-abdominal pressure. Thus, women who exercise do not have stronger pelvic muscles than the ones who do not; actually, the more active women have reported greater incontinence while doing strong-effort and high-impact exercises than those who do not exercise regularly (Bo, 2004b). Athletes should be taught to contract those muscles previously or simultaneously to impact exercises and sports practice. Instructions on this matter are needed because previous studies indicated that one third of females either contract their pelvic muscles incorrectly or have difficulty with doing so. In three different studies, around 30\% of female subjects reported inability to interrupt urinary flow (Bevenute et al., 1987; Bo et al., 1988; Kegel, 1952). This "inability" is associated with urinary leaking. After women were "taught" to contract their PFM while coughing, the authors noticed a significant incontinence reduction; still, no mention to whether women had the same training during sports practice was made (Brown \& Miller, 2001). According to another study, 17 out of 23 women reported a decrease in urinary leaking during jumping and running, after exercising the PFM. All the same, just like the aforementioned study, it was impossible to identify if the PFM exercises were done during and simultaneously to sports practice (Bo, 2004a). More recently, researchers reported a reduction and even a suspension of incontinence complaints in 3 nulliparous athletes (29-33 years old). They had had training for strengthening PFM with specific exercises along with biofeedback; electrical stimulation and vaginal cones. Yet, though athletes were advised to work on the contractions at home every day, this instruction was not described simultaneously to their physical activity and sports practice (Rivalta et al., 2010).

\subsection{Systematic proposal of physical activities for women in general, including pelvic floor exercises}

Due to the lack of researches in Physical Education or of a multidisciplinary project which discussed a PFM strengthening exercise program and considering that physical exercises are likely to become a risk factor for urinary incontinence symptoms, we decided to create a 
physical activity program with PFM exercises (Fig.2). It was first developed in 2003, and improved and applied to a female group afterwards, as part of a research. Its results showed a reduction of incontinence complaints and an improvement of participants' body image (Caetano et al., 2009b). This research project included specific exercises for PFM, plus proprioception exercises (to get a better perception of the pelvis), breathing exercises, recreational activities (such as games and plays), stretching exercises, warm-up exercises (aerobic activities), upper and lower limb, abdominal and gluteus strengthening exercises and relaxation exercises.

This research aimed mainly at creating strategies for the Physical Education professional to develop PFM strengthening exercises during physical exercise and sports practice with students who might or might not have complaints about urinary incontinence, in order to prevent or reduce its symptoms. The Physical Education professionals usually work at venues such as clubs, rehabilitation centers, gyms, schools, indoor or outdoor courts and companies; they also work as sports and fitness coaches for female professional athletes; this means their work involves a wide-ranging population group, which requires PFM exercises suitable to different ages as well as physical activities and exercises focusing on each individual's needs.

One of this systematization first concerns was to characterize the inclusion of PFM exercises in physical exercise and sports practice as a non-therapeutic action under the assumption that the engaged muscles also contain voluntary fibers, contracted according to the individual's will, the same way as upper and lower limbs, pectoral, abdominal, gluteus and calf muscles. The PFM contractions, however, can only be "felt", not observed. Thus, as these muscles are somehow "unknown", most women find it difficult to perform and sense the contractions. Given this, the first step to be taken by women, both, athletes and nonathletes, prior to PFM training, should include proprioception exercises so as to achieve a conscious "recognition" of those muscles and a complete cohesion of this area ("asleep" up until then) with the whole body, favoring the PFM training.

Pelvic Floor Muscles contractions can be obtained by specific procedures, in which these are the only exercised muscles; PFM can also be contracted simultaneously to other exercises which mainly focus on other muscles' strengthening. Simultaneity is handy, especially when there are strong-effort and high-impact exercises, whether competitively or leisurely. PFM simultaneous exercising is possible during body-building activities using specific equipment, free weight-lifting exercises, gym classes, mini-trampoline practice, steps, hydro-gymnastics; and aerobic exercises.

As aforesaid, though some procedures were created in order to help professionals to work with PFM contraction exercises, quite a few researches follow standardized guidelines. Both our proposal and our research follow the instructions published by the Association of Women's Health Obstetrics and Neonatal Nurses (Agency for Health Care Policy and Research, [AWHONN]). According to this protocol, PFM strengthening exercises should include 40 to 50 contractions per session, with a sequence of 8 to 12 slow and quick contractions, where contractions are slow and isometric, 5 seconds long at the beginning and lasting for 10 seconds later on. Long term and daily training can, however, allow more contractions per class or training session, which was detected during our research, in which 
1- hour classes were routinely given twice a week for a four-month period (Caetano et al, 2009b)

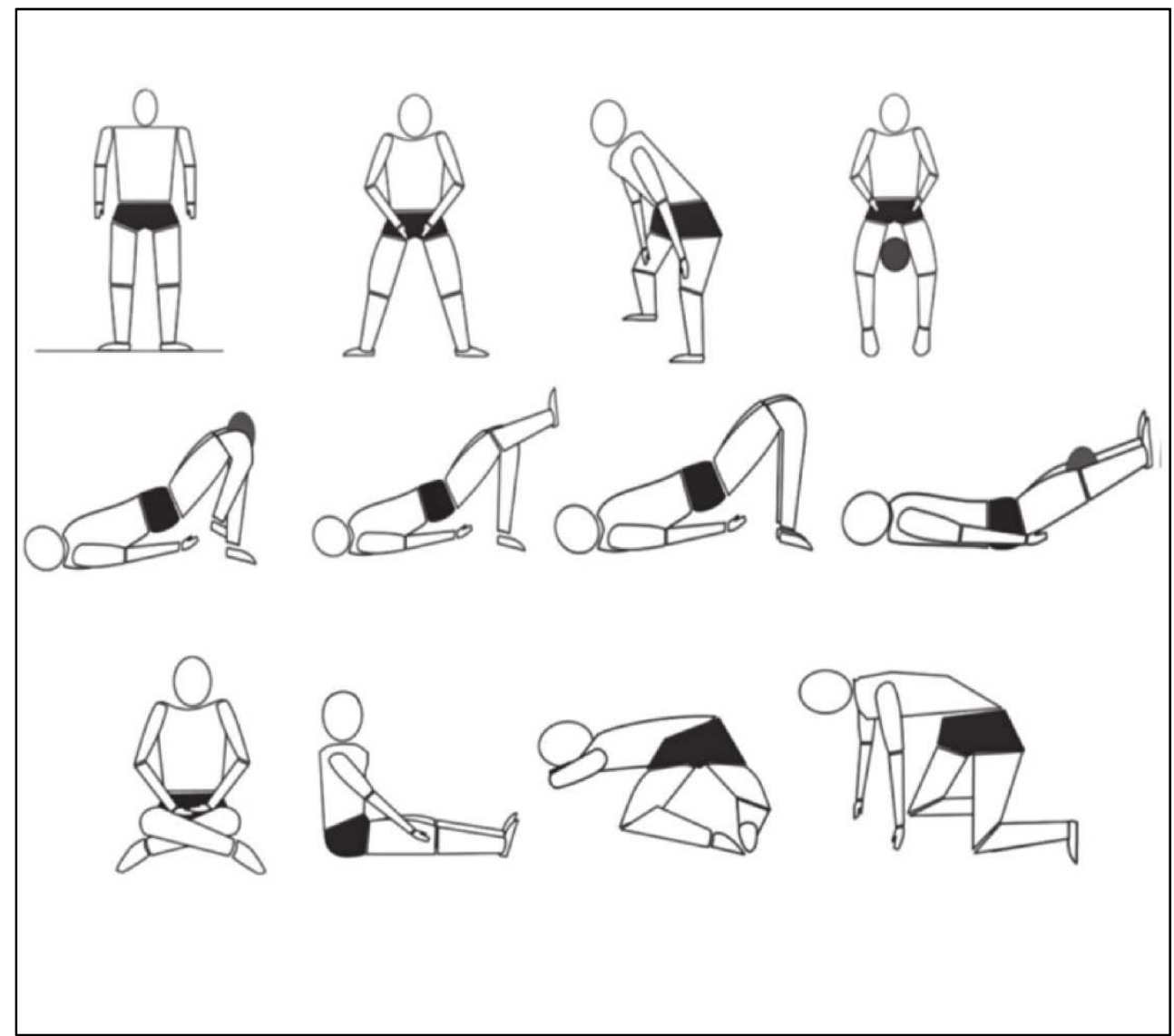

Fig. 2. Pelvic Floor Muscle Exercises (By Artur Paulo Caetano \& Nicholas Silva Caetano). Source: Caetano, A.S. et al.,(2004). Physical Activity Proposal for Stress Urinary Incontinent Women. Lecturas Educacion Fisica y Deportes [online journal] Available:

URL: http://www.efdeportes.com/efd76/mulheres.

\section{Conclusions}

After reviewing the data about the main relationships between urinary incontinence and physical activity and sports practice referred to in this chapter, we identified a high prevalence of urinary incontinence symptoms in women who exercise, significantly higher in young athletes; we also noticed that strong-effort and high-impact exercises are a major cause of incontinence complaints. Though literature is still inconclusive on this matter, these exercises seem to represent a risk factor for the development of urinary incontinence or are likely to aggravate pre-existing symptoms. Just the same, little is known about the pelvic 
floor reactions during several physical activities and also during long term physical practice. Researches aiming to identify pelvic floor reactions to different mid and long term physical exercises should be carried out in the future.

Through our project and a proposal of physical activities (Aletha et al., 2009b) which included PFM training and strengthening exercises, we were able to point out that, besides the results showing a reduction of incontinence complaints and an improvement in the participants' body image, it is also possible to create strategies to be used by Physical Education professionals who train incontinent women. A systematic and integrated physical activity program as described in the previous item allow incontinent women to get a better health and quality of life perception, specially towards their own body image and towards a decrease in incontinence complaints, with a reduction of the amount and frequency of urinary leaking.

Unfamiliarity with the connection between urinary incontinence and physical activity creates a gap in the education of Physical Education professionals and, hence, in their teaching practice. Leaving PFM exercises out of global exercising programs does not seem reasonable, as those muscles are part of every woman's functional activity and deserve attention. Coaches and physical trainers should encourage female athletes and non-athletes to contract the pelvic muscles while exercising because women are quite unlikely to think about it without guidance. Every woman, athlete or not, must stimulate these muscles so as to identify and contract them during gym classes and aerobic exercises, in order to prevent or reduce urinary incontinence and improve bladder control. The coach should always ask his/her athletes about incontinence symptoms resulting from strong-effort and high-impact exercises so as to contribute with strategies which help solve or minimize the problem. Moreover, the coach should help his/her student or athlete become aware of urinary incontinence and of its connection with high impact exercises and sports and make them realize how important it is to strengthen the muscles responsible for female urinary continence. Hence, once they have a coach or instructor who is prepared to discuss these issues, students and athletes will find it safe to share their incontinence first symptoms or existing problems with them. These actions can change physical activity and sports practice into a supporting and even preventing intervention in the treatment of urinary incontinence, helping to reduce prevalence rates and to prevent incontinent women to quit physical activities, making sure they enjoy the benefits of such practice. Controlled studies carried out on future researches are needed, in order to investigate how physical activities, specific PFM exercises included, can bring benefits people with urinary incontinence in the mid and long run.

\section{Acknowledgments}

Faculdade de Educação Física- Universidade Estadual de Campinas- UNICAMP.

Maria Helena Baena de Moraes Lopes.

Maria da Consolação G.C.F. Tavares.

Artur Paulo Caetano.

Nicholas Silva Caetano.

Andrea Castillo. 


\section{References}

Abrams, P.; Cardoso, L.; Fall, M.; Rosier. P.; Ulmsten, U.; Van Kerrebroeck, P.; Victor, A. \& Wein, A. (2003). M. The standardization of terminology of lower urinary tract function: report from the standardization sub-committee of The International Continence Society. Urology, Vol.61, No.1 (January), pp. 37-49, ISSN: 0090-4295.

Agency for Health Care Policy and Research (AHCPR), (1996). Overview urinary incontinence in adults clinical practice guideline update, Retrieved Jun., 7, 2011. Available from: http://www.ahcpr.gov/clinic/uiovervw.htm.

America Heart Association (AHA). (2007).In: Facts and statistics. Retrieved Jun 7, 2011, Available from http:/ / www.americanheart.org/presenter. jhtml?identifier=2321.

Ashton-Miller, J.; Howard, D. \& DeLancey, J.O. (2001) The functional anatomy of the female pelvic floor and stress incontinence control system. Scandinavian Journal of Urology Nephrology Supplementum Vol 207, (March), pp.1-7, ISSN: 0300-8886.

Arvonen, T.; Fianu-Jonasson, A. \& Tyni-Lenne, R. (2000). Effectiveness of two conservative modes of physical therapy in women with urinary stress incontinence. Neurourology and Urodynamic,Vol.19, No.5, (September), pp. 591-599, ISSN: 07332467.

Balmforth, J.; Bidmead, J.; Cardozo, L.; Hextall, A. Kelvin, B. \& Mantle J. (2004). Raising the tone: a prospective observational study evaluating the effect of pelvic floor muscle training on bladder neck mobility and associated improvement in stress urinary incontinence. Neurourology and Urodynamic, Vol., 23, No.5-6, (August) pp.553-554, ISSN: 0733-2467.

Bevenuti, F.; Caputo, G.M. \& Bardinelli S. (1987). Reeducative treatment of female genuine stress incontinence. American Journal Physical Medicine, Vol.66, No.4, (August) pp.155-168, ISSN: 0002-9491.

Bo.; K.; Larsen, S. \& Oseid, S.(1988). Knowledge about and ability to correct pelvic floor muscle exercises in women with urinary stress incontinence. Neurourology and Urodynamic, Vol.7, No.2, (November) pp.261-272, ISSN: 0733-2467.

Bo, K.; Hagen, R.; Kvastein, B. \& Larsen, F. (1989). Female stress urinary incontinence and participation in different sport and social activities. Scandinavian Journal of Sports $\mathcal{E}$ Science, Vol.11, No.1, pp.117-121, ISSN: 1600- 0838.

Bo, K. (1992). Stress urinary incontinence, physical activity and pelvic floor muscle strength training. Scandinavian Journal of Medicine $\mathcal{E}$ Science in Sports, Vol.2, No.4, (December), pp.197-206, ISSN: 1600-0838.

Bo, K. \& Borgen, J.S. (2001). Prevalence of stress and urge urinary incontinence in elite athletes and controls. Medicine and Science in Sports and Exercise, Vol.33, No.11, (November), pp.1797-802, ISSN: 0195-9131.

Bo, K. (2004a).Pelvic floor muscle training is effective in treatment of female stress urinary incontinence, but how does it work? International Urogynecology Journal and Pelvic Floor Dysfunction, Vol.15, No.2, pp.76-84, ISSN: 0937-3462

Bo, K. (2004b). Urinary incontinence, pelvic floor dysfunction, exercise and sport. Sports Medicine, Vol.34, No.7, pp.451-464, ISSN: 0112-1642.

Bo,K.; Morkved, S.; Frawley, H. \& Margaret, S. (2009). Evidence for Benefit of Transversus Abdominis Training Alone or in Combination With Pelvic Floor Muscle Training to 
Treat Female Urinary Incontinence: A Systematic Review. Neurourology and Urodynamics, Vol.28, (February), pp.368-373, ISSN: 0733-2467.

Bo.,K.; Bratland-Sanda, S. \& Borgen, J.S. (2011). Urinary Incontinence Among Group Fitness Instructors Including Yoga and Pilates Teachers Neurourology and Urodynamics, Vol. 30, No.3, (March), pp.370-373, ISSN: 0733-2467.

Brown, W. \& Miller, Y. (2001). Too wet to exercise? Leaking urine as a barrier to physical activity in women. Journal of Science and Medicine in Sport, Vol.4, No.4, (December, pp. 373-378, ISSN: 1440-2440.

Bump, R. \& Norton, P. (1998). Epidemiology and natural history of pelvic floor dysfunction. Obstetrics and Gynecology Clinics of North American,Vol.25, No.4, (December), pp.723746, ISSN: 0889-8545.

Caetano, A.S.; Tavares, M.C.G.C.F.; Lopes, M.H.B.M. (2009a). Urinary incontinence and physical activity practice. Revista Brasileira de Medicina do Esporte, Vol.13, No.4, (Jul), ISSN: 1517-8692.

Caetano, A.S.; Tavares, M.C.G.C.F.; Lopes, M.H.B.M \& Poloni, R.L. (2009b).Influence of Physical Activity in the Quality of Life and Self Image of Incontinent Women. Revista Brasileira d Medicina do Esporte, Vol. 15; No.2, (March), ISSN: 1517-8692.

Cammu, H.; \& Van Nylen, M. (1998). Pelvic floor exercises versus vaginal weight cones in genuine stress incontinence. European Journal of Obstetrics and Gynecology and Reprodution Biolology, Vol.77, No.1, (March), pp.89-93, ISSN: 0301-2115.

Carrol, S.; Dudfield M. (2004). What is the relationship between exercise and metabolic abnormalities? A review of the metabolic syndrome. Sports Medicine, Vol.34, No.6, pp. 371- 418, ISSN: 0112-1642.

Davis, G. (1999). Urinary incontinence among female soldiers. Military Medicine, Vol.164, No.3, (March), pp.182-187, ISSN: 0026-407.

Dumoulin, C.; Lemieux, M.C.; Bourbonnais, D.; Gravel, D.; Bravo, G. \& Morin, M. (2004). Physiotherapy for persistent postnatal stress urinary incontinence: A randomized controlled trial. Obstetrics and Gynecology, Vol.104, No.3, (September), pp.504-510, ISSN: 0029-7844.

Eliasson, K.; Larsson, T. \& Mattsson, E. (2002). Prevalence of stress incontinence in elite trampolinists. Scandinavian Journal of Medicine \& Science in Sports, Vol.12, No.2, (April), pp.106-110, ISSN: 1600-0838.

Eliasson, K.; Edner, A. \& Mattsson, E. (2008). Urinary incontinence in very young and mostly nulliparous women with a history of regular organised high-impact trampoline training: occurrence and risk factors. International Urogynecology Journal and Pelvic Floor Disfunction, Vol.19, (January), pp.687-69, ISSN: 0937-3462.

Fischer, J,R. \& Berg, P.H. (1999). Urinary incontinence in United States Air Force female aircrew. Obstetrics and Gynecology, Vol.94, No.4, (October), pp.532-536, ISSN: 00297844.

Fultz, N.; Burgio, K., Diokno, A.C.; Kinchen, K.; Obenchain, R. \& Bump, R. (2003). Burden of stress urinary incontinence for community-dwelling women. American Journal of Obstetrics Gynecology, Vol.189, No.5, (November), pp.1275-1282, ISSN: 0029-7844.

Gorayeb, N.; Turibio L.B.N. (1999). O exercício: preparação fisiológica, avaliação médica, aspectos especiais e preventivos, Atheneu, ISBN: 857379139, São Paulo, Brazil. 
Grosse, P.D. \& Sengler, J. (2001). Reeducação Perineal. Manole ISBN: 85-204-1162-2,São Paulo, Brazil.

Guyton, A. C. \& HALL, J.E. (1997) Fisiologia Humana e Mecanismos das Doenças Guanabara Koogan ISBN: 85-201-0201-8, Rio de Janeiro, Brazil.

Harris, R.L.; Cundiff, G.W, \& Coates, K.W. (1998). Urinary incontinence and pelvic prolapse in nulliparous women. Obstetrics and Gynecology, Vol.92, No.6, (December), pp.951954, ISSN: 0029-7844.

Hay, J.G. (1993). Citius, altius, longius (faster, higher, longer): the biomechanics of jumping for distance. Journal of Biomechanics, Vol.26, No1, pp.7-21, ISSN: 0021-9290.

Hay-Smith, E.J.C.; Herbison, G.P. \& Wilson, P.D. (2002). Pelvic floor muscle training for women with symptoms of stress urinary incontinence: A randomised trial comparing strengthening and motor relearning approaches. Neurourology and Urodynamic, Vol.21, No.4, (Jul) pp.371-372, ISSN: 0733-2467.

Hextall, A.; Majid, S. \& Cardoso, L. (1999) A prospective controlled study of urinary symptoms in women with several anorexia nervosa. Neurourology and Urodynamic, Vol.18, No.4, (August), pp.398-409, ISSN: 0733-2467.

Hu., T.W.; Wagner, T.H.; Bentkover, J.D.; Leblanc, K.; Zou, S.Z. \& Hubt, T. (2004). Costs of urinary incontinence and overactive bladder in the United States: a comparative study. Urology, Vol.63, No.3, (March), pp.461-465, ISSN: 0090-4295.

Hunskaar, S.; Lose, G. \& Sykes D. (2004) The prevalence of urinary incontinence in four European countries. British Journal of Urology International, Vol.93, No.3, (September), pp. 324-330, ISSN: 0007-1331.

Jiang, K.; Novi, J.M.; Darnell, S. \& Arya, L.A. (2004). Exercise and urinary incontinence in women. Obstetrics and Gynecology Survey, Vol.59, No.10, (October), pp.717-721, ISSN: 0029-7828.

Johnson, V.Y. (2001). Effects of submaximal exercise protocol to recondition the pelvic floor musculature. Nursing Research,Vol.50, No.1, (January), pp.33-41, ISSN: 00296562.

Kegel, A.H. (1952). Stress incontinence and genital relaxation. Ciba Clinical Symposia, Vol.4, No.2, (February), pp.35-52 ISSN: 0362-5060.

Kegel, A.H (1948). Progressive resistance exercise in the functional restoration of the perineal muscles. American Journal of Obstetrics and Gynecology, Vol. 56, No.2, (August), pp.238-248, ISSN: 0002-9378.

Levi D'ancona, C.A. (2001). Diagnostico da Incontinência Urinária na Mulher, In: Aplicações Clinicas da Urodinâmica. C.A. Levi D'ancona \& N. JR., Rodrigues Netto, (Ed.), Atheneu, ISBN: 8573793538, São Paulo, Brazil.

Minassian, V.A.; Drutz, H.P.\& Al-Badr, A. (2003). Urinary incontinence as a worldwide problem. International Journal of Gynecology and Obstetrics, Vol.82, No.3, (September), pp. 327-338, ISSN: 0020-7292.

Moen, M.; Noone, M.; Vassallo, B.; Lopata, R.; Nash, M.; Sum, B. \& Schy, S. (2007) Knowledge and performance of pelvic muscle exercises in women. Female Pelvic Medicine E Reconstructive Surgery, Vol.13, No. (March) pp.113-117, ISSN: 2151-8378. 
Mullins, C.D.; Subak, L.L. (2005). New perspectives on overactive bladder: quality of life impact, medication persistency, and treatment costs. American Journal Management Care, Vol. 11, No.4, (July), pp.101-102, ISSN: 1088-0224.

Neumann, P.B.; Grimmer, K.A. \& Deenadayalan, Y. (2006). Pelvic floor muscle training and adjunctive therapies for the treatment of stress urinary incontinence in women: a systematic Review. BMC Women's Health, Vol.6, No.11, (June), pp.1-28, ISSN: 14726874.

Norton, P.A.; Macdonald, L.D.; Sedgwinck, P.M. \& Stanton, S.L. (1988) Distress and delay associated with urinary incontinence, frequency and urgency in women. British Medical Journal, Vol.297, (November), pp. 1187-1189, ISSN: 0959-8146.

Nygaard, I.E.; Delancey, J.O.\& Arnsdorf L. (1990) Exercise and incontinence. Obstetrics and Gynecology, Vol.75, No.5, (May), pp.848-51, ISSN: 0029-7844.

Nygaard. I.E.; Thompsson, F.L. \& Svengalis S.L. (1994) Urinary incontinence in elite nulliparous athletes. Obstetrics Gynecology, Vol.84, No,2, (August), pp.183-187, ISSN: 0029-7844.

Nygaard, I.E.; Glowacki. C. \& Saltzman, C.L. (1996) Relationship between foot flexibility and urinary incontinence in nulliparous varsity athletes. Obstetrics and Gynecology, Vol. 87, No.6, (June), pp. 1049-1051, ISSN: 0029-7844.

Nygaard,I.E. (1997) Does prolonged high-impact activity contribute to later urinary incontinence? A retrospective cohort study of female Olympians. Obstetrics and Gynecology, Vol.90, no.5, (November), pp.718-722, ISSN: 0029-7844.

Nygaard, I.E.; Girts, T.; Fultz, N.H.; Kinchen, K.; Pohl, G. \& Sternfeld, B. (2005). Is urinary incontinence a barrier to exercise in women? Obstetrics and Gynecology, Vol.106, No.2, (August), pp. 307-314, ISSN: 0029-7844.

Nygaard I.; Thom, D.H. \& Calhoun, E.A. (2007a). Urinary Incontinence in women. In: Urologie Diseases in America, MS. Litwin \& C.S. Saigal (ed.). US Department of Health and Human Services, Public Health Service, National institutes of Health, National Institute of Diabetes and Digestive and Kidney Diseases. Government Printing Office, 2007; NIH Publication No. 07-5512; 159-191, Washington, DC; US.

Nygaard, I.; Handa, V.; Brubaker, L.; Borello-France, D.; Wei, J.; Wells, E. \& Weber, A.M. (2007b). Physical activity in women planning sacrocolpopexy. International Urogynecology Journal and Pelvic Floor Dysfunction, Vol.18, (May), pp. 33-37, ISSN: 0937-3462.

Nygaard, I.; Handa, V.L.; Brubaker, L.; Borello-France, D.; Wei, J.; Wells, E. \& Goode, P. (2008). Changes in physical activity after abdominal sacrocolpopexy for advanced pelvic organ prolapsed for the Pelvic Floor Disorders. American Journal of Obstetrics E Gynecology, Vol.198, (May), pp.570.e1-570-575, ISSN: 0002-9378.

O’Dell, K.; Morse, A.N.; Crawford, S.L. \& Howard, A. (2007). Vaginal pressure during lifting, floor exercises, jogging, and use of hydraulic exercise machines. International Urogynecology Journal and Pelvic Floor Dysfunction, Vol.18, No.12, pp. 1481-1489, ISSN: 0937-3462.

Ortiz, O.C. (2004). Stress urinary incontinence in gynecological practice. International Journal of Gynecology and Obstetrics. Vol.86, No.1 (August), pp.6-16, ISSN: 0020-7292 
Palma, P.C.R. \& Reccetto, C. L. Z. (1999). Incontinência Urinária de Esforço na Mulher, In: Urologia Prática, N.R.JR. Netto, (Ed.), Atheneu, ISBN: 9788572417174. São Paulo, Brazil.

Parkkinen, A.; Karjalainen, E.; Vartiainen, M. \& Penttinen, J. (2004). Physiotherapy for female stress urinary incontinence: Individual therapy at the outpatient clinic versus home-based pelvic floor training: A 5 year follow up study. Neurourology Urodynamic, Vol. 23, No.7, (September), pp.643-648, ISSN: 0733-2467.

Pieber, D.; Zivkovic, F.; Tamussino, K.; Ralph, G.; Lippitt, G. \& Fauland, B. (1995). Pelvic floor exercises alone or with vaginal cones for the treatment of mild to moderated stress urinary incontinence in premenopausal women. International Urogynecology Journal Pelvic Floor Dysfunction, Vol.6, No.1, pp.14-17, ISSN: 0937-3462.

Ree, M.L.; Nyggard, I. \& Bo, K. (2007). Muscular fatigue in the pelvic floor muscles after strenuous physical activity. Acta Obstetricia et Gynecologica Scandinavica, Vol.86, No.7, (December), pp.870 876, ISNN: 0001-6349.

Rivalta, M.; Sighinolfia, M.C.; Salvatore, M.; De Stefano, S.; Francesca, Torcasio, F. \& Giampaolo,B. (2010). Urinary Incontinence and Sport: First and Preliminary Experience With a Combined Pelvic Floor Rehabilitation Program in Three Female Athletes. Health Care for Women International, Vol.31, (April), pp.435-443, ISSN: 0739-9332.

Salvatore, S.; Serati, M.; Laterza; R.; Uccella, S.; Torella, M. \& Bolis, P.F. (2009). The impact of urinary stress incontinence in young and middle-age women practicing recreational sports activity: an epidemiological study. British Journal of Sports Medicine, Vol. 43, (September), pp.1115-1118, ISSN: 0306-3674.

Santos, E.S.; Caetano, A.S.; Tavares, M.C.G.C.F. \& Lopes, M.H.B.M. (2009). Urinary incontinence among physical education students. Revista da Escola de Enfermagem USP, Vol. 43; No. 2, (november), pp. 307-312, ISSN: 0080-6234.

Simeonova, Z.; Milson, I. \& Kullendorf A.M. (1999). The prevalence of urinary incontinence and its influence on the quality of life in women from urban Swedish population. Acta Obstetricia et Gynecologica Scandinavica, Vol.78, No. 6, (June), pp. 546-51, ISSN: 0001-6349.

Stach-Lempinen, B.; Nygard, C.H.; Laippala, R.M.; Metsanoja, R. \& Kujansuu, E. (2004). Is physical activity influenced by urinary incontinence? Obstetrics and Gynecology, Vol.111, No.5, (April), pp.475-480, ISSN: 0020-7292.

Tata, G.E. (1998). Incontinência, In: Fisioterapia na Terceira Idade, B. Pickles; A. Compton; R. Cott; J. Simpson \& A. Vandervoort, Santos, ISBN: 572882189, São Paulo, Brazil.

Turkan, A.; Inci,Y. \& Fazli D. (2005). The short term effects of physical therapy in different intensities of urodynamic stress incontinence. Gynecology Obstetric Investigation, Vol. 59, No.1, pp.43-48, ISSN: 0378-7346.

Thyssen, H.H.; Clevin, L. \& Olosen S. (2002). Urinary incontinence in elite female athletes and dancers. International Urogynecologic Journal and Pelvic Floor Dysfunction, Vol.;13, No.1, pp.15-17, ISSN: 0937-3462.

Wei, J.; Raz, S. \& Young, G.P.H. (1999). Fisiopatologia da Incontinência Urinária de Esforço. In: Urologia Feminina,I. Rubinstein (ed.), BYK, ISBN, São Paulo, Brazil. 
WHO/FIMS (1995). Committee on Physical Activity for Health: Exercise for health. Bullettin of the World Health Organization: The International Journal of Public Health, Vol. 73, pp. 135-136, ISSN: 0042-9686. 


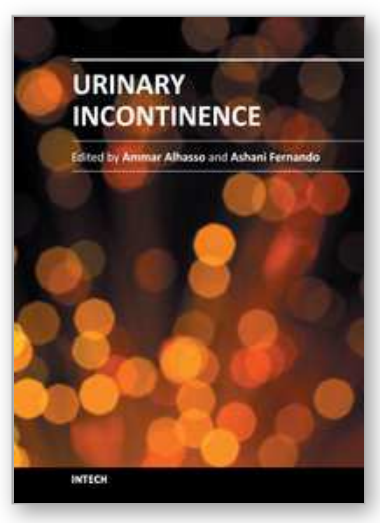

\author{
Urinary Incontinence \\ Edited by Mr. Ammar Alhasso
}

ISBN 978-953-51-0484-1

Hard cover, 324 pages

Publisher InTech

Published online 04, April, 2012

Published in print edition April, 2012

Management strategies are framed within a multidisciplinary team structure and as such a range of specialists ranging from psychologists, specialist nurses, gynaecologists and urologists author the chapters. There are some novel methods outlined by the authors with their clinical application and utility described in detail, along with exhaustive research on epidemiology, which is particularly relevant in planning for the future.

\title{
How to reference
}

In order to correctly reference this scholarly work, feel free to copy and paste the following:

Aletha Caetano (2012). Incontinence[A1]: Physical Activity as a Supporting Preventive Approach, Urinary Incontinence, Mr. Ammar Alhasso (Ed.), ISBN: 978-953-51-0484-1, InTech, Available from: http://www.intechopen.com/books/urinary-incontinence/-female-urinary-incontinence-physical-activity-as-asupporting-preventive-approach-

\section{INTECH}

open science | open minds

\author{
InTech Europe \\ University Campus STeP Ri \\ Slavka Krautzeka 83/A \\ 51000 Rijeka, Croatia \\ Phone: +385 (51) 770447 \\ Fax: +385 (51) 686166 \\ www.intechopen.com
}

\author{
InTech China \\ Unit 405, Office Block, Hotel Equatorial Shanghai \\ No.65, Yan An Road (West), Shanghai, 200040, China \\ 中国上海市延安西路65号上海国际贵都大饭店办公楼405单元 \\ Phone: +86-21-62489820 \\ Fax: $+86-21-62489821$
}


(C) 2012 The Author(s). Licensee IntechOpen. This is an open access article distributed under the terms of the Creative Commons Attribution 3.0 License, which permits unrestricted use, distribution, and reproduction in any medium, provided the original work is properly cited. 